WORK ENVIRONMENT AND BULLYING

\title{
EXAMINING THE RELATIONSHIP BETWEEN THE PERCEIVED WORK ENVIRONMENT AND WORKPLACE BULLYING
}

\author{
CÉLESTE M. BROTHERIDGE \\ Université du Québec à Montréal \\ RAYMOND T. LEE \\ University of Manitoba, Winnipeg
}

\begin{abstract}
This study examined the relationship between perceived work environment variables and bullying behaviours among 180 workers from the public service, elementary school, health care, and potash mine industries located on the Canadian prairies. The results indicate that a heavy workload and a poor team atmosphere predicted a composite measure of bullying as well as two of its components: work being undermined and belittlement. Belittlement was also predicted by low job autonomy and unfair treatment. The findings suggest that potential mechanisms for discouraging aggressive and bullying behaviours are to promote empowerment, coworker support, balanced workloads, and the fair treatment of employees.
\end{abstract}

In the past decade, research on workplace bullying has directed much of its attention on bullying's deleterious effects on employees (Einarsen, Matthiesen, \& Skogstad, 1998; Zapf, Knortz, \& Kulla, 1996). Indeed, the consequences of bullying have been well documented. Compelling evidence exists to show that bullying is strongly associated with stress, depression, anxiety, psychosomatic symptoms (Einarsen et al., 1998), mental health issues (Hoel, Rayner, \& Cooper, 1999), symptomalogy consistent with posttraumatic stress disorders (Leymann \& Gustafsson, 1996), and either suicide or suicide contemplation (Einarsen, Raknes, \& Matthiesen, 1994).

To the extent that the work environment encourages bullying, organizations are legally and morally obligated to ensure that any behaviours that create a hostile work climate are addressed and eliminated (Adams, 1992; Crawford, 1997). Only then can the workplace be considered healthy and

An earlier version of this paper was presented at the $1^{\text {er }}$ colloque canadien de recherche sur la santé et le travail, Montreal, QC in 2005. The authors thank Tricia Flude and Aimee Bernath for their assistance in data collection. This study was completed while Raymond Lee was on sabbatical leave at the Psychology Department, San Francisco State University. 
safe. By understanding the contextual factors in the workplace that may be implicated in the bullying process, we can target workplace interventions for maximum impact. The present study examines how several central elements of the perceived work environment are predictive of the extent to which individuals become the target of bullying behaviours.

\section{Definition of Workplace Bullying}

The literature on interpersonal mistreatment in the workplace encompasses the areas of harassment (Brodsky, 1976), emotional or psychological abuse (Keashly, Trott, \& MacLean, 1994; Keashly, 1998), mobbing (Leyman \& Gustafsson, 1996; Zapf, 1999), petty tyranny (Ashforth, 1994), and bullying (Einarsen et al., 1998; Hoel et al., 1999). Cortina, Magley, Williams, and Langhout (2001) distinguished between the clear intention to harm, which is evident in direct, physical, and active aggression; psychological aggression, which is associated with harassment and hostility; and the less apparent intention to harm expressed through incivility, a mild form of mistreatment that involves, for example, rudeness and discourtesy toward others.

This study defines workplace bullying as a pattern of negative acts that are directed at an individual employee and that are persistent. These negative acts may incorporate actions falling within the rubrics of incivility and aggression (Baron \& Neuman, 1996; Einarsen et al., 1998; Keashly, 1998). As in incivility, the bully's intention to cause humiliation, offence or distress may not always be clear; thus, the bully's intention is of less importance than the cumulative effects of his or her actions. Indeed, Einarsen et al. (1998) argued that bullies tend to engage in acts that allow them to conceal any hostile intentions. In the early stages of bullying, bullies are especially likely to engage in "behaviors that are difficult to pinpoint because they are very indirect and discreet, [but] later on, more direct aggressive acts appear" (Einarsen et al., 1998, p. 564). However, bullying is conceptually broader than incivility in that the former encompasses a wider range of negative behaviours targeted at employees over time and is not simply reflected in mild forms of mistreatment (Cortina et al., 2001).

\section{Work Environment and Bullying}

The present study considers some of the major contextual variables that may contribute to bullying. Although various dispositional attributes of perpetrators may account for some aspects of bullying acts (Brodsky, 1976; Crawford, 1997), conflict, as an inherent aspect of social interactions, is perhaps a more powerful cause of bullying (Aquino, 2000; Crawford, 1997; Zapf, 1999). As argued by Zapf (1999), a high tendency for intra-organizational conflict leads to its escalation, which, in turn, fosters mobbing or bullying behaviours. Severe organizational dysfunction and uncertainty are indicative of entrenched conflict, which heightens the probability of mobbing.

Contextual variables that have potentially strong influences on bullying include a lack of on-thejob control and autonomy (Einarsen et al., 1998; Vartia, 1996) and poor leadership (Ashforth, 1994; Vartia, 1996). Time pressures and the presence of a hectic work environment, in combination with lack of control or autonomy, are conducive to bullying because of the adversarial work climate that they 


\section{WORK ENVIRONMENT AND BULLYING}

create (Einarsen et al., 1994). Regarding leadership, an abuse of power, poor communications, and the abdication of leadership responsibilities are likely to spawn the fertile breeding of bullies (Ashforth, 1994; Einarsen et al., 1994). In contrast, allowing for greater employee involvement in the decisionmaking process and building a climate of constructive teamwork and coworker support may counteract some of the negative effects of dysfunctional conflict and poor leadership (Aquino, 2000; Einarsen et al., 1994; Vartia, 1996).

Baron and Neuman (1996) provided evidence that suggested that many workplace aggressive behaviours were due to certain unwelcome changes in management practices such as increased surveillance of employee performance, pay cuts, downsizing, and the promotion of diversity. These changes undermined employees' sense of control and prompted them to feel that "the system" was being unfair to them through a lack of distributive justice (e.g., rewards not tied to performance), a lack of procedural justice (e.g., low influence in decision-making), and the mistreatment by others at work (Baron $\&$ Neuman, 1996). When there is perceived unfairness in any of these three dimensions, the potential for interpersonal conflict is heightened. To the extent that perceived unfairness leads to intraorganizational conflict, bullying is likely to occur.

Most of the evidence pertaining to the relationship between these contextual variables and bullying is based on research undertaken in Europe (Einarsen et al., 1994; Leymann, 1996; Seigne, 1998; Vartia, 1996; Zapf et al., 1996). Leymann's (1996) examination of Swedish bullying targets isolated four contextual factors: (a) deficiencies in work design, (b) deficiencies in leadership behaviour, (c) the socially exposed position of targets, and (d) low moral standards in a work unit. Similarly, Seigne (1998) found that Irish workers who were bullied reported their workplace to be highly stressful and competitive, plagued with interpersonal conflicts, lacking a friendly and supportive atmosphere, and undergoing organizational changes that were being managed in an authoritarian fashion (cf. Ashforth, 1994). Einarsen et al. (1994) reported that Norwegian workers who were bullied perceived the existence of poor leadership and felt unable to monitor and control their own work tasks. They also believed that the existence of incompatible demands and social expectations in their roles, tasks, and responsibilities created frustration and stress within the workgroup, which, in turn, generated conflict and poor team relations. Vartia (1996) found that Finnish workers who were either targets or observers of bullying described their work units as having a poor communications flow, an authoritative style of conflict management, a lack of discussion regarding goals and tasks, and insufficient opportunities and resources to influence matters concerning themselves.

The foregoing review suggests that deficient job features may have a more proximal relationship to workplace bullying than a poor interpersonal climate. This follows from the likelihood that the role conflict that underlies bullying stems from a combination of excessive job demands and inadequate resources required to meet such demands (Hobfoll, 1989; Zapf, 1999). However, a poor interpersonal climate is likely to have a more proximal relationship to bullying than fair treatment since the latter reflects the broad domain of organizational culture and values and, therefore, is less tied to one-to-one social interactions. Thus, job features have greater prepotency than perceived interpersonal climate, which in turn, has greater prepotency than perceived fairness. The hierarchy of proximal relationships 
to bullying does not imply that climate and fairness are of less ecological significance. Rather, this hierarchy suggests that both impact on bullying only after job features have done so. Hence, the following hypotheses are presently examined:

H1: Perceived deficiencies in job features (low skill utilization, low autonomy, high surveillance, low job involvement, and excessive workload) are positively related to bullying.

H2: Perceived poor interpersonal climate (poor team atmosphere, a lack of supportive leadership, inadequate communications, and interpersonal conflict) are positively related to bullying over-andabove perceived job features.

H3: Perceived unfair treatment (rewards not based on performance, unfair decision-making procedures in place, and general mistreatment by others at work) is positively related to bullying overand-above perceived job features and interpersonal climate.

\section{METHOD}

\section{Participants}

Prior to conducting our study, the design protocol and survey questionnaire were approved by the Research Ethics Board of the University of Regina. Invitations to take part in this research were extended to a convenience sample of workers in a government department, an elementary school, a health care setting, and a potash mine located on the Canadian prairies. Of the 341 individuals invited to take part in the study, 180 individuals completed and mailed the anonymous questionnaires directly to the first author. The 53\% response rate compares favorably with those in similar studies (e.g., $38 \%$ in Salin, 2001; 47.2\% in Matthiesen \& Einarsen, 2001).

Most of the respondents (146) worked full-time. Of the sample, $40 \%$ were clerical workers, $30 \%$ were professionals, and $16 \%$ were managers, with the remaining employed in miscellaneous areas. Of the sample, 108 were female and 104 were married. The sample's mean age was 38 years, mean organizational tenure was 11.4 years, and mean job tenure was six years.

\section{Measures}

Bullying. Because bullying can be expressed through different types of overt actions (Cortina et al., 2001; Lee \& Brotheridge, 2006; Namie, 2000), this study measured workplace bullying as a composite variable comprised of a range of specific behaviours. Bullying by others was measured by 43 items, all drawn from existing scales with the exception of one item (Cortina et al., 2001; Keashly et al., 1994; Keashly \& Jagatic, 2000; Quine, 1999; Rayner, 1997; see Lee \& Brotheridge, 2006, Table 1). Respondents used a 5-point response scale to rate how often each of the 43 behaviours was directed towards them during the past 6 months. A composite bullying scale was computed by summing across the 43 items. In a principal components analysis of the 43 items, three meaningful factors emerged and accounted for $43 \%$ of the common variance (Lee \& Brotheridge, 2006). The first factor was labeled "Belittlement" (13 items); the second factor was labeled "Work Undermined" (7 items); and the third 


\section{WORK ENVIRONMENT AND BULLYING}

factor was labeled "Verbal Abuse" (7 items). Three separate bullying tactic scales were computed based on the results of the principal components analysis.

As documented in Lee and Brotheridge (2006),

$40 \%$ of the sample reported that they had experienced one or more acts of bullying at least once per week within the past 6 months [and] $10 \%$ of the sample reported that they had experienced five or more acts of bullying at least once per week within the past 6 months. ... The foregoing suggests that between $10 \%$ and $40 \%$ of the present sample were targets of bullying or aggressive behaviors. (p. 365)

For all of the predictor measures, respondents used a 5-point response scale to rate how strongly they agreed or disagreed with each of the scale items.

Job features. Skill utilization was measured by a two-item scale derived from Einarsen et al. (1994). Items included "I use my abilities and qualifications in my job," and "I do challenging and interesting work." Autonomy was measured by a two-item scale also derived from Einarsen et al. (1994). Items included "I control how I do my job," and "I do my job without interference from my supervisor." Surveillance was measured by a three-item scale developed for this study based on Greenberg and Barling (1999). Items included "My work is being monitored-electronically or via video camera — on a regular basis," "I punch a time card at work," and "I receive very close supervision." Job involvement was measured by a three-item scale based on Hoel et al. (1999). A sample item is "My supervisor involves me in the decision-making process." Workload was measured by a fouritem scale taken from Kahn et al. (1964). A sample item is "I normally have a very heavy workload."

Interpersonal climate. Team atmosphere was measured by a four-item scale derived from Einarsen (1999) and Einarsen et al. (1994). Items included "I get respect from others at work," "I feel supported by my coworkers," "My coworkers cooperate with me," and "We have a team atmosphere at work." Supportive leadership was measured by a five-item scale taken from Leymann (1996). A sample item is "I receive quality guidance from my supervisor." Inadequate communications were measured by a four-item scale based on Einarsen (1999). Items included "There is poor information flow in our workplace," "Differences of opinion are usually settled in an authoritative way," "People are very competitive in my workplace," and "Interpersonal problems tend to be ignored or downplayed in our workplace." Conflict was measured by a three-item scale taken from Leiter (1988). A sample item is "I rarely encounter conflict with my coworkers."

Fair treatment. This variable was measured by a three-item scale based on Greenberg and Barling (1999). Items included "The procedures used to make the decisions in my organization are fair," "I feel that, in general, I am treated fairly," and "I think that rewards are related to employee performance levels."

\section{Analyses}

Analyses of variance tests indicated that the mean level of bullying (as a composite variable and in its three tactics) did not vary across occupational groups. Thus, occupational grouping was not included as a control variable in the regression analyses. Each hypothesis was examined through the use of fixed effects hierarchical multiple regressions for the composite bullying measure and for each of the three bullying tactics. Fixed effects regression models were used since the response scales were 
specified a priori and the goal was to generalize to only those values. Because the response values were not randomly drawn from a larger universe of possible values, a random effects model was not appropriate and would have had less power to detect significant effects. In each regression equation, the five job features were entered as a block in step 1 . The four interpersonal climate dimensions were entered as a block in step 2 , since they were more distally related to bullying than the five job features. Lastly, fair treatment was entered in step 3, since it was posited to be the most distally related to bullying. The test of $\mathrm{H} 1$ was based on whether the job features explained significant variance in bullying. The test of $\mathrm{H} 2$ was based on whether the interpersonal climate dimensions added to the explained variance over and above job features. Similarly, the test of $\mathrm{H} 3$ was based on whether fair treatment added to the explained variance over and above the job features and interpersonal climate dimensions. The individual regression weights were interpreted after all of the variables were entered in the regression equation.

\section{RESULTS}

Descriptive statistics, estimates of scale internal reliabilities (alphas), and the correlations among all study variables are found in Table 1 . With the exception of surveillance, inadequate communications, and low conflict, the alpha reliability estimates for the study variables were .70 or greater. The bullying subscales were moderately and positively interrelated, thus suggesting that they may be used in combination with each other. The bullying composite and subscale measures were the most strongly associated with a negative team atmosphere and unfair treatment.

$\mathrm{H} 1$ predicted that job features would be positively associated with bullying. Table 2 reveals that the five job features explained $10 \%$ of the variance in composite bullying, $12 \%$ of the variance in belittlement, and $9 \%$ of the variance in work undermined, but only $4 \%$ of the variance in verbal abuse. Thus, $\mathrm{H} 1$ was supported for all but the third bullying tactic.

$\mathrm{H} 2$ predicted that dimensions of the interpersonal climate would be positively associated with bullying over-and-above job features. The results of the significance of the incremental variance (i.e., $F$-due to change) are found in Table 2 . The four interpersonal climate dimensions explained $5 \%$ of the incremental variance in composite bullying, which was significant at the .05 level. The climate dimensions explained $4 \%$ of the incremental variance in belittlement, which was not significant. The climate dimensions explained $5 \%$ of the incremental variance in work being undermined, which was marginally significant at the .07 level. Last, the climate dimensions explained only $1 \%$ of the incremental variance in verbal abuse, which was not significant. Thus, H2 was supported for the composite bullying variable, but only marginally supported for work being undermined.

$\mathrm{H} 3$ predicted that unfair treatment would be positively associated with bullying over-and-above job features and climate dimensions. The results of the significance of the incremental variance test are found in Table 2. Fair treatment explained $1 \%$ of the incremental variance in composite bullying, which was not significant. Fair treatment explained 3\% of the incremental variance in belittlement, which was significant at the .05 level. Fair treatment explained less than $1 \%$ of the incremental variance in each of the two remaining bullying tactics, with neither being significant. Thus, H3 was supported for belittlement only. 


\section{WORK ENVIRONMENT AND BULLYING}

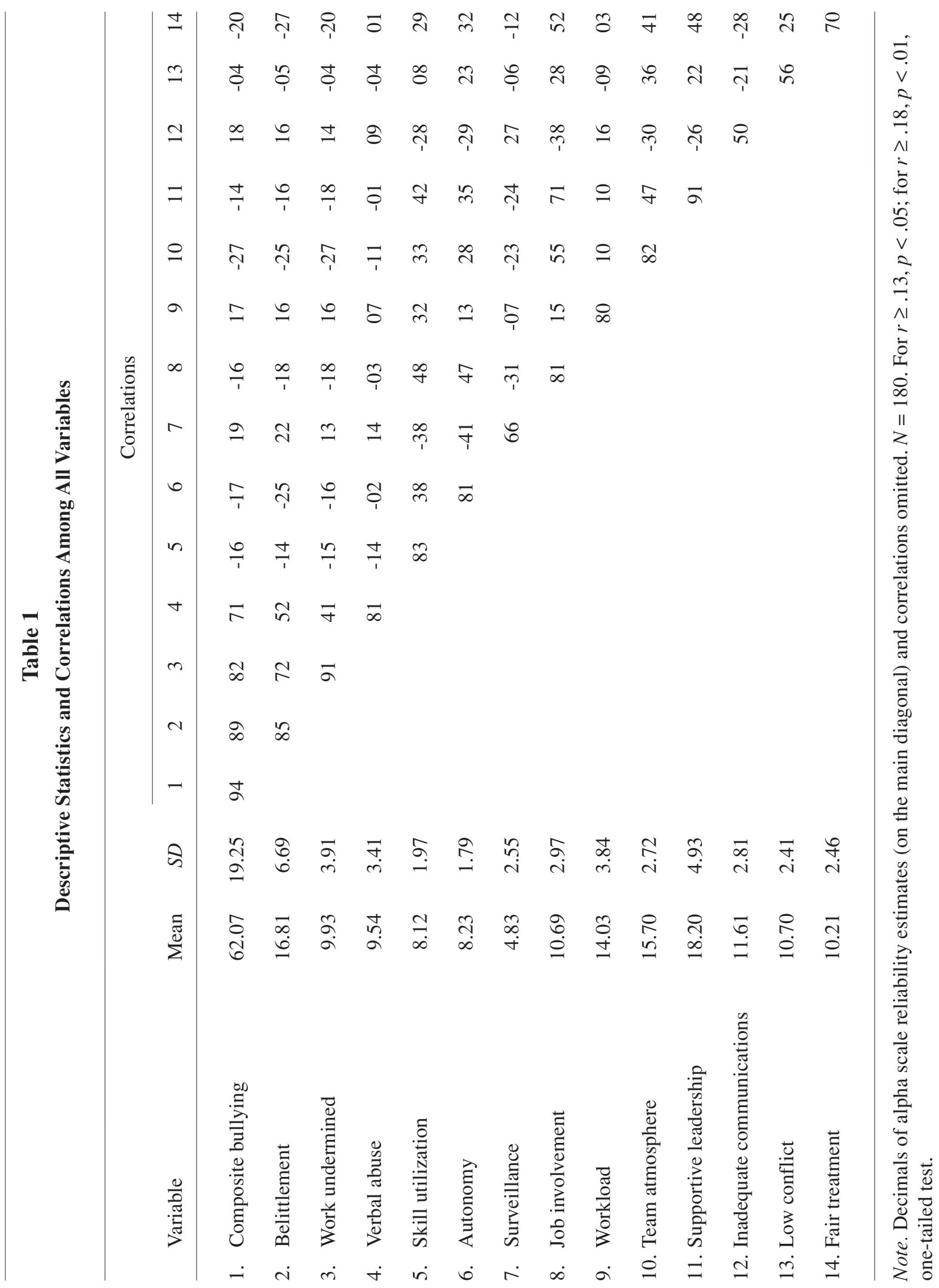


Table 2

Summary of Regression Results

\begin{tabular}{|c|c|c|c|c|}
\hline Model & Composite bullying & Belittlement & Work undermined & Verbal abuse \\
\hline \multicolumn{5}{|l|}{ 1. Job features (step 1) } \\
\hline$R$-square change & .10 & .12 & .09 & .04 \\
\hline$F$-due to change $(5,174)$ & $3.75^{* *}$ & $4.59 * *$ & $3.26 * *$ & 1.50 \\
\hline \multicolumn{5}{|l|}{ 2. Interpersonal climate (step 2) } \\
\hline$R$-square change & .05 & .04 & .05 & .01 \\
\hline$F$-due to change $(4,170)$ & $2.60 *$ & 1.87 & $2.23 \#$ & .53 \\
\hline \multicolumn{5}{|l|}{ 3. Fair treatment (step 3) } \\
\hline$R$-square change & .01 & .03 & .00 & .00 \\
\hline$F$-due to change $(1,169)$ & 1.34 & $5.49 *$ & .72 & .35 \\
\hline Total $R$-square (adjusted $R$-square) & $.16(.11)$ & $.18(.13)$ & $.14(.08)$ & $.06(.00)$ \\
\hline$F$-all variables entered $(10,169)$ & $3.13 * *$ & $3.72 * *$ & $2.64 * *$ & .99 \\
\hline
\end{tabular}

Note. $\# p<.07 . * p<.05 . * * p<.01$. Adjusted $R$-square in parentheses.

The three groups of predictors (10 variables) explained $16 \%$ of the total variance in composite bullying, $18 \%$ of the total variance in belittlement, $14 \%$ of the total variance in work undermined, and only $6 \%$ of the total variance in verbal abuse (Table 2). The full-model equations were significant for all bullying outcomes except verbal abuse.

Table 3 shows the standardized regression weights after all variables were entered for composite bullying, belittlement, and work undermined. Because the regression model for verbal abuse was not significant, the weights were not interpreted. The two predictors that were consistently related to bullying (both as a composite measure and as reflected in separate tactics) were workload (as a job feature) and team atmosphere (as a climate dimension). The heavier the workload, the more frequently bullying was experienced. Conversely, the stronger the team atmosphere, the less frequently bullying was experienced. Similarly, the stronger the perception of autonomy and fair treatment, the less frequently belittlement was experienced.

\section{DISCUSSION}

This study extends research that examines the impact of the work environment on bullying from the target's perspective (Aquino, 2000). Unlike most of the previous research conducted among European workers (Einarsen et al., 1994; Leymann, 1996; Seigne, 1998; Vartia, 1996; Zapf et al., 1996; Zapf, 1999), this study focused on Canadian workers. The participants were sampled from diverse industries (service vs. production, public vs. private sectors) to show that bullying and certain situational antecedents are common to a variety of occupations and professions. In addition to examining bullying as a unitary measure, three separate bullying tactics (cf. Namie, 2000) were included as outcomes. The present findings point to some interesting similarities with and differences from the European studies. 
Table 3

Standardized Regression Weights with All Predictors Included

\begin{tabular}{lccc}
\hline & & Outcome \\
\cline { 2 - 4 } \multicolumn{1}{c}{ Predictor } & Composite bullying & Belittlement & Work undermined \\
\hline 1. Skill utilization & -.13 & -.05 & -.10 \\
2. Autonomy & -.08 & $-.16 \#$ & -.09 \\
3. Surveillance & .08 & .11 & .01 \\
4. Job involvement & .07 & .08 & .02 \\
5. Workload & $.24^{* *}$ & $.23^{* *}$ & $.24^{* *}$ \\
6. Team atmosphere & $-.27^{* *}$ & $-.21^{*}$ & $-.25^{* *}$ \\
7. Supportive leadership & .04 & .04 & -.01 \\
8. Inadequate communications & .01 & -.02 & -.02 \\
9. Low conflict & .10 & .11 & .11 \\
10. Fair treatment & -.10 & $-.20^{*}$ & -.08 \\
\hline
\end{tabular}

Note. $\# p<.07 .{ }^{*} p<.05 .{ }^{* *} p<.01$, one-tailed $t$-test of the raw regression weight.

\section{Major Findings}

The strongest and most consistent relationships were found between a heavy workload, a negative team atmosphere, and bullying. Clearly, uneven distributions in work assignments or loads represent a deficiency in job design and may lead to role conflict. Heavy workloads suggest excessive demands, and any attempt to muster resources to meet such demands creates its own stress (Hobfoll, 1989). Thus, to the extent that members are competing for scarce resources, aggressive behaviours and bullying tendencies may be the unwitting by-products (Baron \& Neuman, 1996).

The association between autonomy and belittlement $(r=-.25, p<.01)$ was intriguing given that their relationship was slightly attenuated by multicollinearity with the other predictors. In the reduced regression model with only the job features entered, a lack of autonomy significantly predicted belittlement (beta $=$ $-.18, p<.05$ ), but in the full model with all variables entered, it did so but marginally (beta $=-.16, p<.07$ ). Nevertheless, it appears that when workers felt in control and free from supervisory interference, they received less frequent belittlement from others. It is as if their job autonomy empowered them to project enough confidence to discourage potential bullies from engaging in aggressive behaviours.

Similarly, a positive team atmosphere may have served as its own confidence booster that reduced the need to fight over scarce resources and, thereby, discouraged interpersonal conflict. In other words, to the extent that workers did not receive support and cooperation from their team members, they were more likely to report frequent acts of bullying behaviours directed at them. This fits with Zapf's (1999) study which found that workers who received low team support also reported experiencing more social stressors and having to deal with higher levels of mobbing than their coworkers.

Unfair treatment was associated with belittlement in this study. A system in which pay was not rewarded commensurate with performance levels and in which decisions were made arbitrarily led not 
only to perceptions of injustice, but also created a zeitgeist for bullies to engage in tactics that would deliberately create self-doubt in their targets' ability and competence. In contrast, in organizations with fair systems, it was more difficult for bullies to attempt to use belittlement tactics as a means of isolating or marginalizing their targets (Baron \& Neuman, 1996).

Caution is needed in inferring causal direction in the present study's results. It is possible that excessive workload was the result of bullying; i.e., bullies may have deliberately assigned unusually heavy workloads to their targets. Similarly, a perceived lack of fair treatment may have been the outcome of belittlement. Targets who are told by bullies that they are incompetent and undeserving of the rewards given to them may attribute this treatment to systemic injustices embedded in organizational policies and procedures. Zapf (1999) tested for this possibility by asking his study participants to complete the job characteristics portion of the questionnaire before answering the mobbing questions. He found that participants who were not the targets of bullying tended to view their job characteristics more favorably than those who were targets. Since the participants were not permitted to change their responses to the job characteristics questions so that they were aligned with their responses to the bullying questions, it seems less likely that bullying led to perceived poor job conditions.

This study provided mixed support for the three hypotheses. Perhaps most surprising was that verbal abuse was not associated with any of the contextual variables. It is possible that verbal abuse, as a form of aggression, may be more fleeting and done in the heat of the moment, and thus is less directly tied to job features or social relations. In contrast, belittlement and undermining targets' work appear to be more insidious and premediated actions designed to hurt the reputation of the targets. During periods of heightened instability and uncertainty, such backbiting and conflicts can escalate more readily (Baron \& Neuman, 1996; Zapf et al., 1996). Indeed, Baron and Neuman (1996) asserted that changes in job features and social relations lead to perceived uncertainty and injustice, which, in combination, facilitate greater workplace aggression.

Contrary to previous studies, communications and conflict were not significantly related to bullying (Seigne, 1998; Vartia, 1996). The lack of significant effects for communications may have been due to the heterogeneity of the items. One item dealt with poor information flow, another with handling opinions in an authoritarian way, while yet another dealt with people being too competitive. Thus, this measure tapped into different aspects of communications that, collectively, did not relate well with each other, as reflected in the scale's low internal consistency estimate of .50. Similarly, the conflict measure was heterogeneous, as it dealt with clients, coworkers, and superiors. Low conflict with one party did not necessarily mean low conflict with either of the other two parties, hence the scale's low consistency estimate of .56. Future research should employ separate subscale measures for these two variables before relating them to bullying.

\section{Limitations and Implications}

In addition to the need to develop more reliable and homogeneous measures, other study limitations should be addressed in future research endeavors. One limitation was the study's reliance on selfreport measures, with its attendant difficulty in verifying participants' perceptions of their work 


\section{WORK ENVIRONMENT AND BULLYING}

environment. Triangulation with coworker perceptions and multiple data sources may allow for the determination of the impact of the "objective" work environment on aggression and bullying (Baron \& Neuman, 1996). However, as noted by Hoel et al. (1999), third-party reports from within an organization are likely to be tainted by its political environment. Hence, future research should solicit the perceptions of neutral third-party observers and perpetrators (i.e., bullies), as was done in Zapf's (1999) study.

Second, the use of cross-sectional data limits our ability to make causal inferences. Given that bullying progresses in stages, different causes and effects may come into play at each stage (Zapf \& Gross, 2001). Zapf and Gross suggested that the process of bullying is akin to conflict escalation. Targets initially attempt to resolve differences with the bullies through problem-solving and rational discussions. When a settlement cannot be reached, attempts to severe relations lead to conflict with the bullies, and escalate to mistrust, lack of respect, and open hostility. The last phase escalates to the point where bullies exhibit overt aggression and destructive actions, and the targets are pressured to leave the organization. Thus, whether organizations can prevent or mitigate such escalation may depend on how well they can promote favorable job characteristics, positive team climate, and the equitable treatment of all employees.

Related to the second point, the search for causes should consider multiple levels of analysis (Aquino, 2000; e.g., Ashforth, 1994). Rather than search for dispositional or individual job characteristics as the primary causes, more attention might be devoted to group- and organizational-level causes (Hoel et al., 1999). Aggressive behaviours may be exhibited by several parties (i.e., mobbing) and more than one person within a workgroup may be targeted by bullies. The potential "ripple effect" on those who witness others being bullied should not be underestimated. Ashforth's (1994) study of petty tyrants suggests that contextual and structural factors within organizations also may sow the seeds of workplace bullying.

Last, the issue of generalizability is raised whenever the response rate is less than perfect. In our study, the rate of 53\%, while comparing favorably with those obtained in other research (e.g., $38 \%$ in Salin, 2001; 47\% in Matthiesen, 2001), still leaves room for potential bias. Because we were unable to ascertain whether the respondents and non-respondents had comparable demographic attributes and work experiences, we are unable to infer if the two groups had similar levels of the contextual predictors and bullying outcomes. Differences in levels on these variables could have led to differential structural relations (i.e., regression coefficients) found between these two groups. In light of this possibility, the robustness of the relationships reported presently clearly requires validation in future studies of workplace bullying.

Despite this study's limitations, several implications for bullying intervention can be derived from the present findings. Instead of concentrating exclusively on changing individual attitudes and dispositions, a more promising, broader approach may be to improve the work environment at the job, team, and organizational levels (Hoel et al., 1999).

Providing greater job autonomy is not only critical for increasing the motivational potential of a job (vis-à-vis the job characteristics model), but it also empowers workers to face potential hostile 
interactions with bullies. The feeling of self-confidence that comes with such empowerment may discourage belittlement and other aggressive behaviours from bullies. Reducing the workload or distributing it equitably will not only reduce role stress, but it may also facilitate greater cooperation and less hostility among coworkers because they now have greater time and energy (both as forms of resources) to interact positively (Hobfoll, 1989). As a result, instead of competing for resources to get their work done, which may fuel conflict, workers would have sufficient resources to help their coworkers complete their work.

At the group level, a cooperative and supportive climate also discourages bullying. A positive team atmosphere empowers members to seek ways to resolve value differences from a problem-solving perspective rather than in an adversarial manner. A problem-solving approach backed by the strength of the team is critical to breaking the conflict-escalation cycle that fosters bullying (Zapf \& Gross, 2001).

At the organizational level, leaders should be mindful of any changes in policies, procedures, and practices that may undermine the fairness with which employees are treated. A lack of fairness in organizations breaks the psychological contract between management and workers (Hoel et al., 1999), thereby offsetting any positive effects of favorable job characteristics and team climates. Workers may feel cheated and retaliate with renewed escalation of aggression (Baron \& Neuman, 1996). As Hoel et al. argue, organizations are compelled to act decisively to staunch the harmful effects of such a poisoned work atmosphere. Inaction and the hope that the bullying problem will "simply go away" are not only an abrogation of moral and legal responsibilities (Adams, 1992; Crawford, 1997), but also carry long-term financial and psychological costs to their members for which society pays the price.

\section{RÉSUMÉ}

Cette étude a pour objectif d'analyser les relations entre le harcèlement psychologique et l'environnememnt de travail comme perçu par 180 travailleures et travailleuses provenant de divers secteurs économiques de l'Ouest canadien: fonction publique, écoles primaires, soins de santé, extraction de la potasse. Les résultats obtenus révèlent qu'une charge de travail excessive et un mauvais esprit d'équipe ont prédit un mesure composite du harcèlement psychologique ainsi que 2 dimensions spécifiques: la dévalorisation du travail des collègues et la dépréciation d'autrui. Les données révèlent également que la dépréciation d'autrui est tributaire d'une faible autonomie au travail ainsi que du traitement inéquitable. Cette étude propose que pour réduire l'agression et le harcèlement psychologique, on pourrait miser sur la promotion du pouvoir d'agir, sur le soutien entre les collègues de travail, sur la détermination d'une charge de travail raisonnable et sur le traitement équitable des employés et employées.

\section{REFERENCES}

Adams, A. (1992). Bullying at work: How to confront and overcome it. London: Virago.

Aquino, K. (2000). Structural and individual determination of workplace targetization: The effects of hierarchical status and conflict management style. Journal of Management, 26, 171-193.

Ashforth, B.E. (1994). Petty tyranny in organizations. Human Relations, 47, 755-778.

Baron, R.A., \& Neuman, J.H. (1996). Workplace violence and workplace aggression: Evidence on their relative frequency and potential causes. Aggressive Behavior, 22, 161-173. 


\section{WORK ENVIRONMENT AND BULLYING}

Brodsky, C. (1976). The harassed worker. Lexington, MA: D.C. Heath.

Cortina, L.M., Magley, V.J., Williams, J.H., \& Langhout, R.D. (2001). Incivility in the workplace: Incidence and impact. Journal of Occupational Health Psychology, 6, 64-80.

Crawford, N. (1997). Bullying at work: A psychoanalytic perspective. Journal of Community and Applied Social Psychology, 7, 219-226.

Einarsen, S. (1999). The nature of causes of bullying at work. International Journal of Manpower, 20(1/2), 16-28.

Einarsen, S., Matthiesen, S., \& Skogstad, A. (1998). Bullying, burnout and well-being among assistant nurses. Journal of Occupational Health and Safety, 14, 563-568.

Einarsen, S., Raknes, B.I., \& Matthiesen, S. (1994). Bullying and harassment at work and their relationships to work environment quality: An exploratory study. European Journal of Work and Organizational Psychology, 4, 381-401.

Greenberg, L., \& Barling, J. (1999). Predicting employee aggression against coworkers, subordinates, and supervisors: The roles of person behaviors and perceived workplace factors. Journal of Organizational Behavior, 20, 897-913.

Hobfoll, S.E. (1989). Conservation of resources: A new attempt at conceptualizing stress. American Psychologist, 44, 513-524.

Hoel, H., Rayner, C., Cooper, C.L. (1999). Workplace bullying. International Review of Industrial and Organizational Psychology, 14, 195-230.

Kahn, R., Wolfe, D., Quinn, R., Snoeck, J., \& Rosenthal, R. (1964). Organizational stress: Studies in conflict and ambiguity. New York: John Wiley.

Keashly, L. (1998). Emotional abuse in the workplace: Conceptual and empirical issues. Journal of Emotional Abuse, 1, 85-117.

Keashly, L., \& Jagatic, K. (2000). The nature, extent, and impact of emotional abuse in the workplace: Results of a statewide survey. Paper presented at the annual meeting of the Academy of Management, Toronto, Canada.

Keashly, L., Trott, V., \& MacLean, L. (1994). Abusive behavior in the workplace: A preliminary investigation. Violence and Targets, 9, 341-357.

Lee, R.T., \& Brotheridge, C.M. (2006). When prey turns predatory: Workplace bullying as a predictor of counteraggression/bullying, coping and well-being. European Journal of Work and Organizational Psychology, 15, 352-377.

Leiter, M.P. (1988). Burnout as a function of communication patterns: A study of a multidisciplinary mental health team. Group \& Organization Studies, 13, 111-128.

Leymann, H. (1996). The content and development of mobbing at work. European Journal of Work and Organizational Psychology, 5, 165-184.

Leymann, H., \& Gustafsson, A. (1996). Mobbing at work and the development of post-traumatic stress disorders. European Journal of Work and Organizational Psychology, 5, 251-275.

Matthiesen, S.B., \& Einarsen, S. (2001). MMPI-2 configurations among victims of bullying at work. European Journal of Work and Organizational Psychology, 10, 467-484.

Namie, G. (2000). U.S. hostile workplace survey, 2000: Survey results. Retrieved May 9, 2005, from Campaign Against Workplace Bullying website: www.bullybusters.org/home/

Quine, L. (1999). Workplace bullying in NHS community trust staff questionnaire survey. British Medical Journal, 318, 228.

Rayner, C. (1997). The incidence of workplace bullying. Journal of Community and Applied Social Psychology, 7, 199-208.

Salin, D. (2001). Workplace bullying among professionals: Gender differences in terms of prevalence and forms. Paper presented at the $16^{\text {th }}$ Nordic Academy of Management Meeting, Uppsala.

Seigne, E. (1998). Bullying at work in Ireland. In C. Rayner, M. Sheehan, \& M. Barker (Eds.), Bullying at work, 1998 research update conference proceedings. Stafford, UK: Staffordshire University.

Vartia, M. (1996). The sources of bullying: Psychological work environment and organizational climate. European Journal of Work and Organizational Psychology, 5, 203-214.

Zapf, D. (1999). Organisational, work group related and personal causes of mobbing/bullying at work. International Journal of Manpower, 20, 70-84. 


\section{CANADIAN JOURNAL OF COMMUNITY MENTAL HEALTH}

Zapf, D., \& Gross, C. (2001). Conflict escalation and coping with workplace bullying: A replication and extension. European Journal of Work and Organizational Psychology, 10, 497-522.

Zapf, D., Knortz, C., \& Kulla, M. (1996). On the relationship between mobbing factors and job content, social work environment, and health outcomes. European Journal of Work and Organization, 5, 215-238. 